\title{
A comparative analysis of different hybrid MCDM techniques considering a case of selection of 3D printers
}

\author{
Debapriyo Paul*, Puneet Kumar Agarwal, Gourab Gopal Mondal and Debamalya Banerjee
}

Department of Production Engineering, Jadavpur University, India

\begin{tabular}{l}
\hline C H R O N I C L E \\
\hline Article history: \\
Received January 25, 2015 \\
Received in revised format 28 \\
March 2015 \\
Accepted 3 May 2015 \\
Available online \\
May 72015 \\
\hline Keywords: \\
3D Printing \\
ANP \\
TOPSIS \\
Similarity Method \\
PROMETHEE \\
Hybrid MCDM \\
Comparative analysis \\
\hline
\end{tabular}

\section{A B S T R A C T}

A multitude of techniques fall under the domain of Multi- Criteria Decision Making (MCDM) which is used to select the best alternative among the available ones. The objective of this paper is to compare some of these techniques with respect to the problem of selection of 3D printers, which is associated with multiple attributes. The weights of the criteria were determined using analytical network process (ANP). Next, the alternatives were ranked using three different MCDM techniques- 1.TOPSIS which ranks alternatives having the shortest distance to the ideal solution as well as the greatest distance from the negative-ideal solution 2. Deng's Similarity based Approach where the most preferred alternative should have the highest degree of similarity to the positive ideal solution and the lowest degree of similarity to the negative-ideal solution and 3.PROMETHEE and GAIA. The solutions for each of these three cases were analyzed thoroughly, and reasons for any deviations were discussed.

\section{Introduction}

3D printing is one of different available processes to make a three-dimensional object where additive processes are implemented, in which successive layers of material are laid down under computer control. These objects are in any shape or geometry. Before printing a 3D model from an STL file, it needs to be tested for manifold errors. Especially STL's that have been produced from a model obtained through 3D scanning may contain some manifold errors, which need to be corrected. After that, the STL file requires some process by a software called a slicer, which converts the model into a series of thin layers and generates a G-code file containing instructions tailored to a specific kind of 3D printer. This G-code file can then be printed with 3D printing client software, which loads the G-code, and applies to instruct the 3D printer during the 3D printing process. The 3D printer follows the G-code instructions to lay down successive layers of liquid, powder, paper or sheet material to prepare the model from a series of cross sections. These layers, associated with the virtual cross sections from the CAD model, are joined or automatically fused to build the final shape. The main advantage of this

\footnotetext{
* Corresponding author.

E-mail address: dpsphs@gmail.com (D. Paul) 
technique is the ability to build almost any type of shape or geometric feature. Construction of a model with contemporary techniques can take up to several days, depending on the method applied and the size and complexity of the model. Additive systems can basically reduce this time to a few hours, although it differs widely depending on the kind of machine implemented and the size and number of models being produced, simultaneously.

The three-dimensional (3D) printing is one of the most promising technologies aiming at more flexible inexpensive manufacturing to maintain desired qualities. As stated by Campbell et al. (2011), “3D Printing/Additive Manufacturing (AM) is a revolutionary emerging technology that could up-end the last two centuries of approaches to design and manufacturing with profound geopolitical, economic, social, demographic, environmental, and security implications". The market for 3D printers and services is small but growing rapidly and with the bigger number of alternatives in the market, it is becoming increasingly important to choose the most appropriate one according to reduced cost and the value of customization. This paper deals with the application of three Multi Criteria Decision Making (MCDM) techniques, TOPSIS, Deng's Similarity based method \& PROMETHEE (Preference Ranking Organization Method for Enrichment Evaluations) are used for the selection of the appropriate 3D printer and a comparative analysis of three methods on the basis of the rankings are obtained.

Past works in this field have concentrated on the selection of Rapid Prototyping (RP) machines with the help of other MCDM techniques such as TOPSIS. Bhutia and Phipon (2012) applied TOPSIS to select supplier. Product quality, delivery time, service time and price were chosen as decision criteria. Weights of them were determined by using analytical hierarchy process (AHP). Cheng and Li (2004) used analytical network process (ANP) method for allotting weights to the criteria for section of contractor, which is a more complicated construction management issue. Deng (2007) used the similarity based approach for purchasing fleet jet fighters and a ranking order quite different from that obtained by using TOPSIS emerged out. This approach was however established as one with strong theoretical background. Amponsah et al. (2012) has applied PROMETHEE method to solve a facility location problem and Gaussian as well as Logistic Preference function was used. They observed that both of these preference function produced same ranking order. Karande and Chakraborty (2012) applied PROMETHEE to select the best NTM process and PROMETHEE -GAIA based graphical approach was used. This reduced mathematical computation to a great extent and made complex decision making problem quite easy. Usual type preference unction was used here. Shahroudi and Rouydel (2012) used ANP- TOPSIS multi-criteria decision making approach to evaluate suppliers in Iran's auto industry. Panda et al. (2014) used integrated ANP and Fuzzy TOPSIS technique for selection of Rapid Prototyping Process. Caterino et al. (2009) carried out a detailed comparative analysis of various MCDM methods for seismic Structural Refitting. However no research has yet been performed for selection of 3d printers by utilizing MCDM techniques.

The main objective of this paper is to solve any MCDM problem by using hybrid decision making method where by weights of the criteria obtained by using ANP is utilized for ranking alternatives by TOPSIS, Similarity based approach and PROMETHEE. This paper is aimed at obtaining ranking of alternatives of a 3D printer selection problem by using all these mentioned methods, the purpose being to have a comparative study of all these methods on the basis of different ranking orders obtained.

\section{Methods}

\subsection{ANP}

The Analytic Hierarchy Process (AHP) is a theory of relative measurement with absolute scales of both tangible and intangible criteria based on the judgment of knowledgeable and expert people as stated by Saaty (1988). How to measure intangibles is the main concern of the mathematics of the AHP. The Analytic Network Process (ANP) as discussed by Saaty (2001) is a generalization of the Analytic Hierarchy Process (AHP), by considering the dependence between the elements of the hierarchy. Many 
decision issues cannot be structured hierarchically because they involve the interaction and dependence of higher-level elements in a hierarchy on lower-level elements. Therefore, ANP is represented by a network, rather than a hierarchy.

\subsection{TOPSIS}

TOPSIS (Technique of Order Preference by Similarity to Ideal Solution) method was originally introduced by Hwang and Yoon (1981) and received praise from surveyors and operators. TOPSIS is a decision making technique for finding the alternative that is closest to the ideal solution. In this method, options are graded based on ideal solution similarity. If an option is more similar to an ideal solution, it has a higher grade. Ideal solution is a solution that is the best from any aspect that does not exist practically and we try to approximate it. Basically, for measuring similarity of a design (or option) to ideal level and non-ideal, we consider distance of that design from ideal and non-ideal solution.

Step 1: Determine the decision matrix:

$$
\left[\begin{array}{cccc}
\mathrm{x}_{11} & \mathrm{x}_{12} & \ldots & \mathrm{x}_{1 \mathrm{~m}} \\
\mathrm{x}_{21} & \mathrm{x}_{22} & \ldots & \mathrm{x}_{2 \mathrm{~m}} \\
\cdots & \ldots & \mathrm{x}_{\mathrm{ij}} & \cdots \\
\mathrm{x}_{\mathrm{n} 1} & \mathrm{x}_{\mathrm{n} 2} & \ldots & \mathrm{x}_{\mathrm{nm}}
\end{array}\right]
$$

where $\mathrm{x}_{\mathrm{ij}}$ is the performance of $i^{\text {th }}$ alternative with respect to the $j^{\text {th }}$ criteria. Here $m$ is the number of alternatives and $n$ is the number of criteria.

Step 2: Construct normalized decision matrix. This step transforms various attribute dimensions into non-dimensional attributes, which helps comparisons across criteria. Normalize scores or data as follows,

$$
r_{i j}=\frac{x_{i j}}{\sum_{i=1}^{n} x_{i j}^{2}}
$$

Step 3: Construct the weighted normalized decision matrix by multiplying the normalized decision matrix by its associated weights. The weighted normalized value $v_{i j}$ is calculated as:

$v_{i j}=w_{j} x_{i j}$ for $j=1,2, \ldots, n$ where $w_{j}$ is the weight of the criteria $j$. This weight or priority is determined by ANP as discussed above.

Step 4: Determine the positive ideal and negative ideal solution.

\section{Positive ideal solution:}

$$
A^{*}=\left\{v_{1}^{*}, \ldots \ldots, v_{2}^{*}\right\} \text { where, } v_{j}^{*}=\max \left(\mathrm{v}_{\mathrm{ij}}\right) \text { if } \mathrm{j} \in \mathrm{J}^{+} \text {or, } \min \left(\mathrm{v}_{\mathrm{ij}}\right) \text { if } \mathrm{j} \in \mathrm{J}^{-}
$$

\section{Negative ideal solution:}

$$
A^{\prime}=\left\{v_{1}^{\prime}, \ldots \ldots, v_{2}^{\prime}\right\} \text { here } v_{j}^{\prime}=\min \left(\mathrm{v}_{\mathrm{ij}}\right) \text { if } \mathrm{j} \in \mathrm{J}^{+} \text {or, } \max \left(\mathrm{v}_{\mathrm{ij}}\right) \text { if } \mathrm{j} \in \mathrm{J}^{-}
$$

where $\mathrm{J}^{+}$is associated with beneficial criteria and $\mathrm{J}^{-}$is associated with non-beneficial criteria.

Step 5: Calculate the separation measure: 
Separation from positive ideal one:

$$
S^{+}=\sqrt{\sum_{j=1}^{n}\left(v_{i j}-v_{j}^{*}\right)^{2}}
$$

Separation from negative ideal solution:

$$
S_{i}^{-}=\sqrt{\sum_{j=1}^{n}\left(v_{i j}-v_{j}^{\prime}\right)^{2}}
$$

Step 6: Relative closeness to the alternative can be determined as:

$$
C_{i}^{*}=S_{i}^{-} /\left(S_{i}^{+}+S_{i}^{-}\right)
$$

Step 7: Select an alternative with maximum $C_{i}^{*}$ or alternative in the descending order based on the value of $C_{i}^{*}$.

\subsection{Deng’s Similarity Method}

This similarity-based method suggested by Deng (2007) effectively makes use of the ideal solution concept in such a way that the most preferred alternative should have the highest degree of similarity to the positive ideal solution and the lowest degree of similarity to the negative-ideal solution. Using this method, a conflict index is calculated between two alternatives to show the degree of conflict between the alternatives. $A_{i}$ and $A_{j}$ are the two alternatives concerned in a given multi-criteria analysis problem, these two alternatives can be considered as two vectors in the m-dimensional real space. The angle between $A_{i}$ and $A_{j}$ in the m-dimensional real space, shown in Fig. 1 is a good measure of conflict between them.

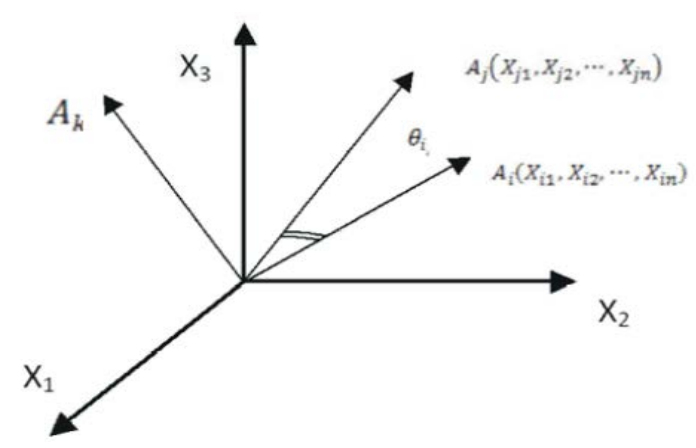

Fig.1. Degree of conflict between alternatives

Step 1: Determine the decision matrix as follows:

$$
\mathrm{X}=\left[\begin{array}{cccc}
\mathrm{x}_{11} & \mathrm{x}_{12} & \ldots & \mathrm{x}_{1 \mathrm{~m}} \\
\mathrm{x}_{21} & \mathrm{x}_{22} & \ldots & \mathrm{x}_{2 \mathrm{~m}} \\
\ldots & \ldots & \mathrm{x}_{\mathrm{ij}} & \ldots \\
\mathrm{x}_{\mathrm{n} 1} & \mathrm{x}_{\mathrm{n} 2} & \ldots & \mathrm{x}_{\mathrm{nm}}
\end{array}\right]
$$

Step 2: Determine the weighting vector as

$$
\mathrm{W}=\left(\mathrm{w}_{1}, \mathrm{w}_{2}, \ldots, \mathrm{w}_{\mathrm{j}}, \ldots, \mathrm{wm}_{\mathrm{m}}\right)
$$


Step 3: Normalize the decision matrix by the following equation:

$$
X_{i j}=\frac{x_{i j}}{\sqrt{\sum_{k=1}^{n} x_{i k}^{2}}}
$$

Normalized decision matrix will be:

$$
\mathrm{X}=\left[\begin{array}{cccc}
x_{11}^{\prime} & x_{12}^{\prime} & \ldots & x_{1 m}^{\prime} \\
x_{21}^{\prime} & x^{\prime}{ }_{22} & \ldots & x^{\prime}{ }_{2 m} \\
\ldots & \ldots & x_{i j}^{\prime} & \ldots \\
x^{\prime}{ }_{n 1} & x^{\prime}{ }_{n 2} & \ldots & x_{n m}^{\prime}
\end{array}\right]
$$

Step 4: Calculate the performance matrix as expressed as:

$$
Y=\left[\begin{array}{cccc}
w_{1} x^{\prime}{ }_{11} & w_{2} x^{\prime}{ }_{12} & \ldots & w_{m} x^{\prime}{ }_{1 m} \\
w_{1} x^{\prime}{ }_{12} & w_{2} x^{\prime}{ }_{22} & \ldots & w_{m} x^{\prime}{ }_{2 m} \\
\ldots & \ldots & w_{j} x^{\prime}{ }_{i j} & \ldots \\
w_{1} x^{\prime}{ }_{1 n} & w_{2} x^{\prime}{ }_{n 2} & \ldots & w_{m} x^{\prime}{ }_{n m}
\end{array}\right]=\left[\begin{array}{cccc}
y_{11} & y_{12} & \ldots & y_{1 m} \\
y_{21} & y_{22} & \ldots & y_{2 m} \\
\ldots & \ldots & y_{i j} & \ldots \\
y_{n 1} & y_{2 n} & \ldots & y_{n m}
\end{array}\right]
$$

Step 5: Determine the positive ideal solution and the negative ideal solution by following equations:

\section{Positive ideal solution:}

$$
A^{*}=\left\{y_{1}^{*}, \ldots \ldots, y_{n}^{*}\right\} \text { where, } y_{j}^{*}=\max \left(y_{\mathrm{ij}}\right) \text { if } \mathrm{j} \in \mathrm{J}^{+} \text {or, } \min \left(\mathrm{y}_{\mathrm{ij}}\right) \text { if } \mathrm{j} \in \mathrm{J}^{-}
$$

\section{Negative ideal solution:}

$$
A^{\prime}=\left\{y_{1}^{\prime}, \ldots \ldots, y_{n}^{\prime}\right\} \text { where, } y_{j}^{\prime}=\min \left(y_{\mathrm{ij}}\right) \text { if } \mathrm{j} \in \mathrm{J}^{+} \text {or, } \max \left(\mathrm{y}_{\mathrm{ij}}\right) \text { if } \mathrm{j} \in \mathrm{J}^{-}
$$

$\mathrm{J}^{+}$is associated with beneficial criteria and $\mathrm{J}^{-}$is associated with non-beneficial criteria.

Step 6: Calculate the degree of conflict between each alternative and positive ideal solution as:

$$
\begin{aligned}
& \cos \theta_{i}^{+}=\frac{\sum_{j=1}^{m} y_{i j * I_{j}^{+}}}{\sqrt{\sum_{j=1}^{m} y_{i j}^{2} \sum_{j=1}^{m}\left(I_{j}^{+}\right)^{2}}} \mathrm{i}=1,2, \ldots, \mathrm{n} \\
& \cos \theta_{i}^{-}=\frac{\sum_{j=1}^{m} y_{i j * I_{j}^{-}}}{\sqrt{\sum_{j=1}^{m} y_{i j}^{2} \sum_{j=1}^{m}\left(I_{j}^{-}\right)^{2}}} \mathrm{i}=1,2, \ldots \ldots, \mathrm{n}
\end{aligned}
$$

Step 7: Calculate the degree of similarity between alternatives and the positive ideal solution and the negative-ideal solution by

$$
\left|C_{i}\right|=\frac{\sum_{j=1}^{m} y_{i j * I_{j}^{+}}}{\sqrt{\sum_{j=1}^{m} y_{i j}^{2} \sum_{j=1}^{m}\left(I_{j}^{+}\right)^{2}}} * \sqrt{\sum_{j=1}^{m} y_{i j}^{2}}
$$




$$
S_{i}^{\mp}=\frac{\left|C_{i}\right|}{\left|A_{i}^{\mp}\right|}=\cos \theta_{i}^{\mp} * \frac{\sqrt{\sum_{j=1}^{m} y_{i j}^{2}}}{\sqrt{\sum_{j=1}^{m} y_{i j}^{\mp 2}}} \quad \mathrm{i}=1,2, \ldots, \mathrm{n}
$$

Step 8: Calculate the overall performance index for each alternative across all criteria by:

$$
P_{i}=S_{i}^{+} /\left(S_{i}^{+}+S_{i}^{-}\right)
$$

Step 9: Rank the alternatives in the descending order of the index value.

\subsection{PROMETHEE}

Preference Ranking Organization Method for Enrichment Evaluation (PROMETHEE) is a well established decision support system which deals with the appraisal and selection of a set of options on the basis of several criteria with the objective of obtaining a ranking among them. PROMETHEE can simultaneously deal with qualitative and quantitative criteria. It can deal with uncertain and fuzzy information. It was founded by Brans and Vincke (1985).

Step 1: PROMETHEE method starts with the decision matrix:

$$
\left[\begin{array}{cccc}
f_{1}\left(a_{1}\right) & f_{2}\left(a_{1}\right) & \ldots & f_{n}\left(a_{1}\right) \\
f_{1}\left(a_{2}\right) & f_{2}\left(a_{2}\right) & \ldots & f_{n}\left(a_{2}\right) \\
\ldots & \ldots & f_{j}\left(a_{i}\right) & \ldots \\
f_{1}\left(a_{m}\right) & f_{2}\left(a_{m}\right) & \ldots & f_{n}\left(a_{m}\right)
\end{array}\right]
$$

where $f_{j}\left(a_{i}\right)$ is the performance of the $\mathrm{i}^{\text {th }}$ alternative with respect to the $\mathrm{j}^{\text {th }}$ criteria. Here $\mathrm{n}$ is the number of the criteria and $\mathrm{m}$ is number of the alternatives. First, a specific preference function needs to be defined $\left(\mathrm{P}_{\mathrm{j}}(\mathrm{a}, \mathrm{b})\right)$ that translates the deviation between the evaluations of two alternatives $(\mathrm{a}$ and $\mathrm{b})$ on a particular criterion $f_{j}$ into a preference degree ranging from 0 to 1 . This preference index is a nondecreasing function of the observed deviation (d) between the scores of the alternatives on the considered criterion $f_{j}(a)-f_{j}(b)$ ), as shown in Eq. (1). In order to facilitate the selection of a specific preference function, six possible shapes of preference functions are proposed to the decision-maker by Brans (1986). They are usual shape, U-shape function, V-shape function, level function, linear function and Gaussian function.

$$
P_{j}(a, b)=G_{j}\left(f_{j}(a)-f_{j}(b)\right)
$$

Step 2: In this method the preference is based on the pair-wise comparison of alternatives for each criterion. For this comparison purpose deviation of evaluations of two alternatives are used where higher the deviation higher will be the preference of one alternative to the other, regarding that criteria. This step involves calculation of preference function $P_{j}(\mathrm{a}, \mathrm{b})$. There are mainly six types of generalized preference functions as proposed by Brans and Mareschal (1990). But these preference functions require the definition of some preferential parameters, such as the preference and indifference thresholds criterion and also to determine the parameters involved.

$$
P_{j}(a, b)=\left\{\begin{array}{cc}
0 & \text { if } \mathrm{f}_{\mathrm{j}}(a)<f_{j}(b) \\
\left(f_{j}(a), f_{j}(b)\right) & \text { otherwise }
\end{array}\right.
$$

For concrete case we define $p($.$) function as:$

$p\left(\left(f_{j}(a), f_{j}(b)\right)=\left(f_{j}(a)-f_{j}(b)\right.\right.$ 
In order to indicate clearly the areas of indifference in the neighborhood of $f(b)$ :

$x=f(a)-f(b)$

\section{Type 1: Usual criteria:}

$P(x)=\left\{\begin{array}{cc}0 & \forall x \leq 0 \\ 1 & \text { otherwise }\end{array}\right.$

\section{Type 2: Quasi criteria:}

$P(x)=\left\{\begin{array}{cc}0 & \forall x \leq l \\ 1 & \text { otherwise }\end{array}\right.$

Type 3: Criteria with linear preference:

$P(x)=\left\{\begin{array}{cc}x / m & \forall x \leq m \\ 1 & \forall x>l\end{array}\right.$

Type 4: Level criteria:

$P(x)=\left\{\begin{array}{cc}0 & x \leq q \\ 0.5 & q<x \leq q+p \\ 1 & x>q+p\end{array}\right.$

Type 5: Criteria with linear preference and indifference area:

$P(x)=\left\{\begin{array}{cc}0 & x \leq s \\ (x-s) / r & s<x \leq s+r \\ 1 & s+r \leq q+p\end{array}\right.$

\section{Type 6: Gaussian Criteria}

$P(x)=\left\{\begin{array}{cc}0 & \forall x \leq 0 \\ 1-e^{-x^{2} / 2 \sigma^{2}} & \forall x>0\end{array}\right.$

The value of $\sigma$ is to be determined the decision maker.

In this paper, only usual criteria and criteria with linear preference have been used.

Step 3: Calculate the overall preference index taking into account weight of the individual criteria. It is calculated as follows:

$$
\pi(a, b)=\sum_{j=1}^{j=n} w_{j} P_{j}(a, b)
$$

Here $\pi(a, b)$ measures the degree with which alternative $a$ is preferred to $b^{\prime}$ and $\pi(a, b)$ the measure of the degree with which alternative $b$ is preferred to the alternative $i$.

Step 4: Determine the leaving and entering outflow matrix. Leaving or positive ranking outflow for the $i^{\text {th }}$ alternative

$$
\varphi^{+}(i)=\frac{1}{n-1} \sum_{b} \pi(a, b)
$$

Entering or negative ranking outflow for the $i^{\text {th }}$ alternative

$$
\varphi^{-}(i)=\frac{1}{n-1} \sum_{b} \pi(b, a)
$$


where $\mathrm{m}$ is the number of alternatives.

\subsection{The PROMETHEE II complete ranking}

Here, each alternative faces $(n-1)$ number of other alternatives. The leaving flow expresses how much an alternative dominates the other alternatives, while the entering flow denotes how much an alternative is dominated by the other alternatives. Based on these outranking flows, the PROMETHEE I method can provide a partial preorder of the alternatives, whereas, the PROMETHEE II method can give the complete preorder by using a net flow, though it loses much information of preference relations.

Step 5: Determine the net outranking flow for each alternative from the following expression:

$$
\varphi(a)=\varphi^{+}(a)-\varphi^{-}(a)
$$

A higher value of $\varphi(a)$ signifies better alternative. Thus, the best alternative has always the highest $\varphi(a)$ value. From the positive and negative outranking flows, the net outranking flow value can be reformulated, as follows:

$$
\begin{aligned}
& \varphi(a)=\varphi^{+}(a)-\varphi^{-}(a) \\
& \varphi(a)=\frac{1}{m-1} \sum_{j=1}^{n}\left(\sum_{b}\left[P_{j}(a, b)-P_{j}(b, a)\right]\right)
\end{aligned}
$$

Thus, $\varphi(a)=\sum_{j=1}^{n} w_{j} \varphi_{j}(a)$

where, $\varphi_{j}(a)=\sum_{b}\left[P_{j}(a, b)-P_{j}(b, a)\right]$

where $\varphi_{j}(a)$ is the single criterion net flow obtained for $j^{t h}$ criterion. It is observed that the global net

\begin{tabular}{|c|c|c|c|c|c|c|}
\hline & \multicolumn{6}{|c|}{ PARAMETERS } \\
\hline 3D PRINTERS & $\begin{array}{l}\text { C1. } \\
\text { Print } \\
\text { Volume } \\
\text { (cu. inch.) }\end{array}$ & $\begin{array}{l}\text { C2. } \\
\text { Max. print } \\
\text { Speed } \\
(\mathrm{mm} / \mathrm{sec})\end{array}$ & $\begin{array}{l}\text { C3. } \\
\text { Layer } \\
\text { Thickness } \\
(\mu \mathrm{m})\end{array}$ & $\begin{array}{l}\text { C4. } \\
\text { No. of } \\
\text { Extruders }\end{array}$ & $\begin{array}{l}\text { C5. } \\
\text { Price } \\
\text { per Unit } \\
\text { (Rs.) }\end{array}$ & $\begin{array}{l}\text { C6. } \\
\text { Manufacturer } \\
\text { Filament Price } \\
\text { (PLA) (Dollars/Kg) }\end{array}$ \\
\hline $\begin{array}{l}\text { A1. MAKERBOT } \\
\text { REPLICATOR MINI }\end{array}$ & $3.9 \times 3.9 \times 4.9$ & 80 & 200 & 1 & 146400 & 48 \\
\hline $\begin{array}{l}\text { A2. PRINTRBOT } \\
\text { SIMPLE }\end{array}$ & $6 \times 6 \times 6$ & 80 & 100 & 1 & 73100 & 30 \\
\hline A3. ULTIMAKER 2 & $9 \times 8.5 \times 8$ & 300 & 20 & 1 & 255500 & 42 \\
\hline $\begin{array}{l}\text { A4. XYZ DA VINCI } \\
1.0\end{array}$ & $7.8 \times 7.8 \times 7.8$ & 150 & 100 & 1 & 77400 & 46.65 \\
\hline $\begin{array}{l}\text { A5. MAKERBOT } \\
\text { REPLICATOR } 5.0\end{array}$ & $9.9 \times 7.8 \times 5.9$ & 100 & 100 & 1 & 289800 & 48 \\
\hline A6. ALFINIA $\mathrm{H}$ & $5 \times 5 \times 5$ & 30 & 150 & 1 & 127600 & 31.99 \\
\hline A7. UP PLUS 2 & $5.5 \times 5.5 \times 5.3$ & 30 & 150 & 1 & 167100 & 56.4 \\
\hline A8. DITTO PRO & $8.7 \times 6.5 \times 8.7$ & 120 & 50 & 1 & 192800 & 44.99 \\
\hline $\begin{array}{l}\text { A9. AIRWOLF } \\
\text { AW3D HD }\end{array}$ & $12 \times 8 \times 12$ & 150 & 60 & 1 & 301600 & 48 \\
\hline A10. FELIX 3.0 & $10 \times 8 \times 9$ & 200 & 50 & 1 & 203100 & 32.6 \\
\hline $\begin{array}{l}\text { A11. CUBIFY } \\
\text { CUBEPRO }\end{array}$ & $\begin{array}{l}11.2 \times 10.6 \times 9 \\
.06\end{array}$ & 15 & 70 & 1 & 283500 & 99 \\
\hline A12. MBOT GRID 2 & $10 \times 9.0 \times 7.8$ & 120 & 100 & 2 & 146700 & 29.16 \\
\hline
\end{tabular}
flow of an alternative is the scalar product of vector of the criteria weights and profile vector of that alternative. This property is primarily used for developing the GAIA plane.

Fig. 2. Different 3D Printer Parameters values 
For large number of alternatives it is impossible to determine the relative position of the alternatives with respect to the criteria. In GAIA plane the alternatives are represented by points and the criteria are represented by axes. The net flow is projection of single criteria net flow vector on w. So the relative position of projections of all the alternatives on $w$ determines the complete ranking. On the GAIA plane $\mathrm{w}$ is represented as projection of unit vector of weights of all the criteria. This projection is represented as $\pi$ axis. The $\pi$ axis directs towards the compromise solution. When more number of criteria are correlated a longer $\pi$ axis will make the ranking an easy one with greater accuracy. A shorter $\pi$ axis resulting from more number of conflicting criteria will make the selection of a good compromise solution hard and will yield a solution of lesser accuracy.

\section{Results}

In the following table (Fig. 2), different types of available 3D printers alongwith their corresponding values of parameters have been shown. The following data have been collected from the manufacturer's website and brochures/ manuals.

\subsection{Determination of relative weights of criteria using ANP}

The relative weights of criteria, judging the selection of suitable 3D printer for educational institutions, can be determined using an ANP Network of Nodes and Clusters. The clusters include goal, criteria and alternatives. The alternatives' cluster is composed of different 3D printers among which the best one has to be chosen. The priorities list has been laid out in Table 1.

\section{Table 1}

ANP priorities list

\begin{tabular}{lll}
\hline Criteria & Normalized by cluster & Limiting \\
\hline C1 & 0.12627 & 0.03261 \\
C2 & 0.12808 & 0.03308 \\
C3 & 0.13254 & 0.03423 \\
C4 & 0.08029 & 0.02074 \\
C5 & 0.32645 & 0.08432 \\
C6 & 0.20637 & 0.05330 \\
\hline
\end{tabular}

\subsection{TOPSIS Results}

Table 2 shows the decision matrix. Table 3 shows the normalized matrix. Table 4 shows weighted normalized matrix with weights (as determined by using ANP in previous section) of the criteria and Table 5 shows the POSITIVE ideal and negative ideal solution regarding each criteria, and ranks the alternatives. According to TOPSIS, XYZ Da Vinci 1.0 emerges out to be the best solution and Cubify Cubepro emerges out to be the worst solution.

\subsection{Deng’s Similarity Method Results}

Here the Similarity based approach has been used to rank the 3D printers. The Ultimaker 2.0 emerges as the best solution here and the UP Plus 2.0 is the worst solution.

\subsection{PROMETHEE Results}

A problem of selecting a 3-D printer is solved using Visual PROMETHEE software. Preference parameters have been stated in Table 8. Visual PROMETHEE REPORT is shown in Table 9. Here Mbot Grid emerges out as the best solution, Da Vinci as second choice and Cubify Cubepro is the worst solution as displayed in this Table 9. In the GAIA plane, shown in Fig. 3, a long decision axis indicates a strong decision power which in turns indicates the chosen criteria are not conflicting. Price and filament price and are well correlated but on the other hand, price and speed, speed and volume are not 
correlated as these axes are orthogonal. However performance of Airwolf and Replicator 5 are better regarding volume criteria. The performance of Replicator mini and Alfinia $\mathrm{H}$ are almost similar. In Fig. 4, a complete ranking of the alternatives as obtained by using PROMETHEE II is shown. In this figure net outranking flow of respective alternatives are also shown.

Table 2

Decision matrix

\begin{tabular}{lllllll}
\hline Alternatives & C1 & C2 & C3 & C4 & C5 & C6 \\
\hline A1 & 74.529 & 80 & 200 & 1 & 146400 & 48 \\
A2 & 216 & 80 & 100 & 1 & 73100 & 30 \\
A3 & 637.2 & 300 & 20 & 1 & 255500 & 42 \\
A4 & 474.552 & 150 & 100 & 1 & 77400 & 46.65 \\
A5 & 455.598 & 100 & 100 & 1 & 289800 & 48 \\
A6 & 125 & 30 & 150 & 1 & 127600 & 31.99 \\
A7 & 160.325 & 30 & 150 & 1 & 167100 & 56.4 \\
A8 & 491.985 & 120 & 50 & 1 & 192800 & 44.99 \\
A9 & 1152 & 150 & 60 & 1 & 301600 & 48 \\
A10 & 720 & 200 & 50 & 1 & 203100 & 32.6 \\
A11 & 1075.6 & 15 & 70 & 1 & 283500 & 99 \\
A12 & 702 & 120 & 100 & 2 & 146700 & 29.16 \\
\hline
\end{tabular}

Table 3

Normalized decision matrix

\begin{tabular}{lllllll}
\hline Objective & Max C1 & Max C2 & Min C3 & Max C4 & Min C5 & Min C6 \\
\hline A1 & 0.0344 & 0.1673 & 0.5366 & 0.2582 & 0.2075 & 0.2785 \\
A2 & 0.0999 & 0.1673 & 0.2683 & 0.2582 & 0.1036 & 0.174 \\
A3 & 0.2948 & 0.6274 & 0.5336 & 0.2582 & 0.3622 & 0.2437 \\
A4 & 0.2196 & 0.3137 & 0.2683 & 0.2582 & 0.1097 & 0.2707 \\
A5 & 0.2108 & 0.2091 & 0.2683 & 0.2582 & 0.4108 & 0.2785 \\
A6 & 0.0578 & 0.0627 & 0.4024 & 0.2582 & 0.1809 & 0.1856 \\
A7 & 0.0741 & 0.0627 & 0.4024 & 0.2582 & 0.2369 & 0.3272 \\
A8 & 0.2276 & 0.2509 & 0.1341 & 0.2582 & 0.2733 & 0.2611 \\
A9 & 0.5331 & 0.3137 & 0.1609 & 0.2582 & 0.4275 & 0.2785 \\
A10 & 0.5331 & 0.4182 & 0.1341 & 0.2582 & 0.2879 & 0.1891 \\
A11 & 0.4977 & 0.0313 & 0.1878 & 0.2582 & 0.4019 & 0.5745 \\
A12 & 0.3248 & 0.2509 & 0.2683 & 0.5165 & 0.2079 & 0.1692 \\
\hline
\end{tabular}

\section{Table 4}

Weighted normalized decision matrix

\begin{tabular}{lllllll}
\hline Columns & C1 $(+)$ & C2 $(+)$ & C3(-) & C4(+) & C5(-) & C6(-) \\
Weights & 0.12808 & 0.12627 & 0.13254 & 0.08029 & 0.32645 & 0.20637 \\
\hline 1 & 0.00440595 & 0.021124971 & 0.071120964 & 0.020730878 & 0.067738375 & 0.057474045 \\
2 & 0.01279519 & 0.021124971 & 0.035560482 & 0.020730878 & 0.03382022 & 0.03590838 \\
3 & 0.03775798 & 0.079221798 & 0.007104144 & 0.020730878 & 0.11824019 & 0.050292369 \\
4 & 0.02812637 & 0.039610899 & 0.035560482 & 0.020730878 & 0.035811565 & 0.055864359 \\
5 & 0.02699926 & 0.026403057 & 0.035560482 & 0.020730878 & 0.13410566 & 0.057474045 \\
6 & 0.00740302 & 0.007917129 & 0.053334096 & 0.020730878 & 0.059054805 & 0.038302272 \\
7 & 0.00949073 & 0.007917129 & 0.053334096 & 0.020730878 & 0.077336005 & 0.067524264 \\
8 & 0.02915101 & 0.031681143 & 0.017773614 & 0.020730878 & 0.089218785 & 0.053883207 \\
9 & 0.06827945 & 0.039610899 & 0.021325686 & 0.020730878 & 0.139557375 & 0.057474045 \\
10 & 0.04266345 & 0.052806114 & 0.017773614 & 0.020730878 & 0.093984955 & 0.039024567 \\
11 & 0.06374542 & 0.003952251 & 0.024891012 & 0.020730878 & 0.131200255 & 0.118559565 \\
\hline 12 & 0.04160038 & 0.031681143 & 0.035560482 & 0.041469785 & 0.067868955 & 0.034917804 \\
\hline PIS & 0.06827945 & 0.079221798 & 0.007104144 & 0.041469785 & 0.03382022 & 0.034917804 \\
NIS & 0.00440595 & 0.003952251 & 0.071120964 & 0.020730878 & 0.139557375 & 0.118559565 \\
\hline
\end{tabular}


Table 5

Ranking of alternatives using TOPSIS

\begin{tabular}{lllll}
\hline Alternatives & \multicolumn{1}{c}{$S_{i}^{+}$} & \multicolumn{1}{c}{$S_{i}^{+}$} & $C_{i}^{+}$ & Ranks \\
\hline A1 & 0.116801 & 0.095835 & 0.45069979 & 9 \\
A2 & 0.087719 & 0.140148 & 0.61504299 & 4 \\
A3 & 0.093406 & 0.126455 & 0.57515885 & 5 \\
A4 & 0.069742 & 0.133389 & 0.65666491 & 1 \\
A5 & 0.12767 & 0.077719 & 0.37839904 & 11 \\
A6 & 0.109571 & 0.112165 & 0.51244571 & 7 \\
A7 & 0.118594 & 0.082668 & 0.41074818 & 10 \\
A8 & 0.088112 & 0.104614 & 0.54281208 & 6 \\
A9 & 0.117858 & 0.107528 & 0.47708376 & 8 \\
A10 & 0.074395 & 0.122878 & 0.62288301 & 3 \\
A11 & 0.151365 & 0.075685 & 0.33334067 & 12 \\
A12 & 0.070292 & 0.12642 & 0.64266542 & 2 \\
\hline
\end{tabular}

Table 6

Performance matrix for similarity based approach

\begin{tabular}{lllllllllll}
\hline $\begin{array}{l}\text { 3D } \\
\text { PRINTER }\end{array}$ & C1 & C2 & C3 & C4 & C5 & C6 & $\cos \theta^{+}$ & $\cos \theta^{-}$ & $S_{i}^{+}$ & $S_{i}^{+}$ \\
\hline A1 & 0.004 & 0.021 & 0.071 & 0.021 & 0.068 & 0.057 & 0.53 & 0.94 & 0.51 & 0.56 \\
A2 & 0.013 & 0.021 & 0.036 & 0.021 & 0.034 & 0.036 & 0.72 & 0.89 & 0.40 & 0.31 \\
A3 & 0.038 & 0.079 & 0.007 & 0.021 & 0.118 & 0.050 & 0.81 & 0.77 & 1.03 & 0.61 \\
A4 & 0.028 & 0.040 & 0.036 & 0.021 & 0.036 & 0.056 & 0.83 & 0.82 & 0.62 & 0.38 \\
A5 & 0.027 & 0.026 & 0.036 & 0.021 & 0.134 & 0.057 & 0.6 & 0.93 & 0.77 & 0.74 \\
A6 & 0.007 & 0.008 & 0.053 & 0.021 & 0.059 & 0.038 & 0.51 & 0.95 & 0.38 & 0.44 \\
A7 & 0.009 & 0.008 & 0.053 & 0.021 & 0.077 & 0.068 & 0.52 & 0.99 & 0.50 & 0.59 \\
A8 & 0.029 & 0.032 & 0.018 & 0.021 & 0.089 & 0.054 & 0.73 & 0.91 & 0.69 & 0.53 \\
A9 & 0.068 & 0.040 & 0.021 & 0.021 & 0.140 & 0.057 & 0.73 & 0.84 & 1.03 & 0.73 \\
A10 & 0.043 & 0.053 & 0.018 & 0.021 & 0.094 & 0.039 & 0.83 & 0.8 & 0.84 & 0.51 \\
A11 & 0.064 & 0.004 & 0.025 & 0.021 & 0.131 & 0.119 & 0.61 & 0.93 & 0.95 & 0.89 \\
A12 & 0.042 & 0.032 & 0.036 & 0.041 & 0.068 & 0.035 & 0.83 & 0.82 & 0.72 & 0.44
\end{tabular}

Table 7

Ranking of 3D printers using similarity based approach

\begin{tabular}{lll}
\hline 3D PRINTER & Pi & RANKS \\
\hline A3 & 0.628 & 1 \\
A10 & 0.623 & 2 \\
A4 & 0.619 & 3 \\
A12 & 0.618 & 4 \\
A9 & 0.584 & 5 \\
A2 & 0.565 & 6 \\
A8 & 0.564 & 7 \\
A11 & 0.515 & 8 \\
A5 & 0.511 & 9 \\
A1 & 0.475 & 10 \\
A6 & 0.464 & 11 \\
A7 & 0.457 & 12 \\
\hline
\end{tabular}


Table 8

PROMETHEE preference parameters

\begin{tabular}{|c|c|c|c|c|c|c|}
\hline ACTIVE & yes & yes & yes & yes & yes & yes \\
\hline & VOLUME & SPEED & THICKNESS & EXTRUDERS & PRICE & $\begin{array}{l}\text { FILAMENT } \\
\text { PRICING }\end{array}$ \\
\hline MIN/MAX & $\max$ & $\max$ & $\min$ & $\max$ & $\min$ & $\min$ \\
\hline WEIGHT & 12.81 & 12.63 & 13.26 & 8.00 & 32.65 & 20.64 \\
\hline $\begin{array}{l}\text { PREFERENCE } \\
\text { FUNCTION }\end{array}$ & Liner & Liner & Liner & Usual & Liner & Liner \\
\hline Thresholds & absolute & absolute & absolute & absolute & absolute & absolute \\
\hline Q. Indifference & 281.498 & 68.35 & 42.17 & $\mathrm{n} / \mathrm{a}$ & 61372.864 & 19.06 \\
\hline P. Preference & 695.402 & 159.18 & 100.81 & $\mathrm{n} / \mathrm{a}$ & 156172.864 & 37.46 \\
\hline S. Gaussian & $\mathrm{n} / \mathrm{a}$ & $\mathrm{n} / \mathrm{a}$ & $\mathrm{n} / \mathrm{a}$ & $\mathrm{n} / \mathrm{a}$ & $\mathrm{n} / \mathrm{a}$ & $\mathrm{n} / \mathrm{a}$ \\
\hline
\end{tabular}

Table 9

Ranking of 3D printers using PROMETHEE

\begin{tabular}{llll}
\hline Actions & Phi & Phi+ & Phi- \\
\hline Mbot Grid 2 & 0.2192 & 0.2568 & 0.0376 \\
Xyz Da Vinci & 0.1828 & 0.2315 & 0.0487 \\
Printrbot simple & 0.1417 & 0.2176 & 0.0759 \\
Feilix 3 & 0.1153 & 0.1790 & 0.0637 \\
Ultirmaker & 0.0908 & 0.2280 & 0.1371 \\
Ditto Pro & 0.0386 & 0.1144 & 0.0758 \\
Alfinia H & -0.0202 & 0.1413 & 0.1615 \\
Airwolf & -0.0467 & 0.1680 & 0.2147 \\
Replicator mini & -0.0915 & 0.1125 & 0.2040 \\
UP Plus 2 & -0.1125 & 0.0882 & 0.2007 \\
Replicator 5 & -0.1926 & 0.0410 & 0.2335 \\
Cubify Cubepro & -0.3249 & 0.1103 & 0.4352 \\
\hline
\end{tabular}

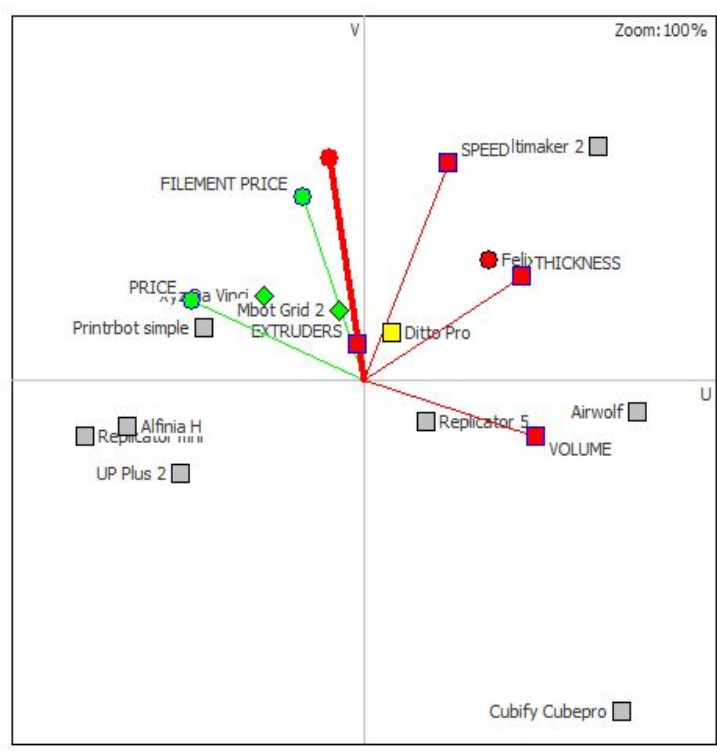

Fig. 3. GAIA Analysis

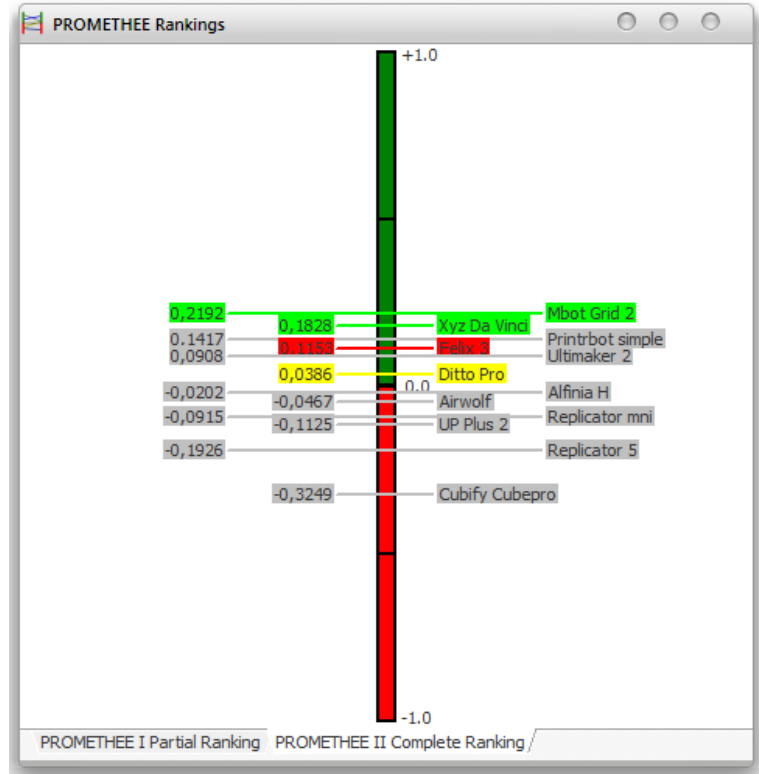

Fig. 4. PROMETHEE II Complete Ranking 
Table 10

Comparative analysis of rankings 3D PRINTERS

$\begin{array}{lll}\text { RANKS BY } & \text { RANKS BY } & \text { RANKS BY } \\ \text { TOPSIS } & \text { SIMILARITY BASED } & \text { PROMETHEE } \\ & \text { APPROACH }\end{array}$

\begin{tabular}{|l|l|l|l}
\hline A1MAKERBOT REPLICATOR MINI & 9 & 10 & 9 \\
\hline A2 PRINTRBOT SIMPLE & 4 & 6 & 3 \\
\hline A3 ULTIMAKER 2 & 5 & 1 & 5 \\
\hline A4 XYZPRINTING DA VINCI 1.0 & 1 & 3 & 2 \\
\hline A5 MAKERBOT REPLICATOR 5.0 & 11 & 9 & 11 \\
\hline A6 ALFINIA H & 7 & 11 & 7 \\
\hline A7 UP PLUS 2 & 10 & 12 & 10 \\
\hline A8 DITTO PRO & 6 & 7 & 6 \\
\hline A9AIRWOLF AW3D HD & 8 & 5 & 8 \\
\hline A10FELIX 3.0 & 3 & 2 & 4 \\
\hline A11CUBIFY CUBEPRO & 12 & 8 & 12 \\
\hline A12 MBOT GRID & 2 & 4 & 1 \\
\hline
\end{tabular}

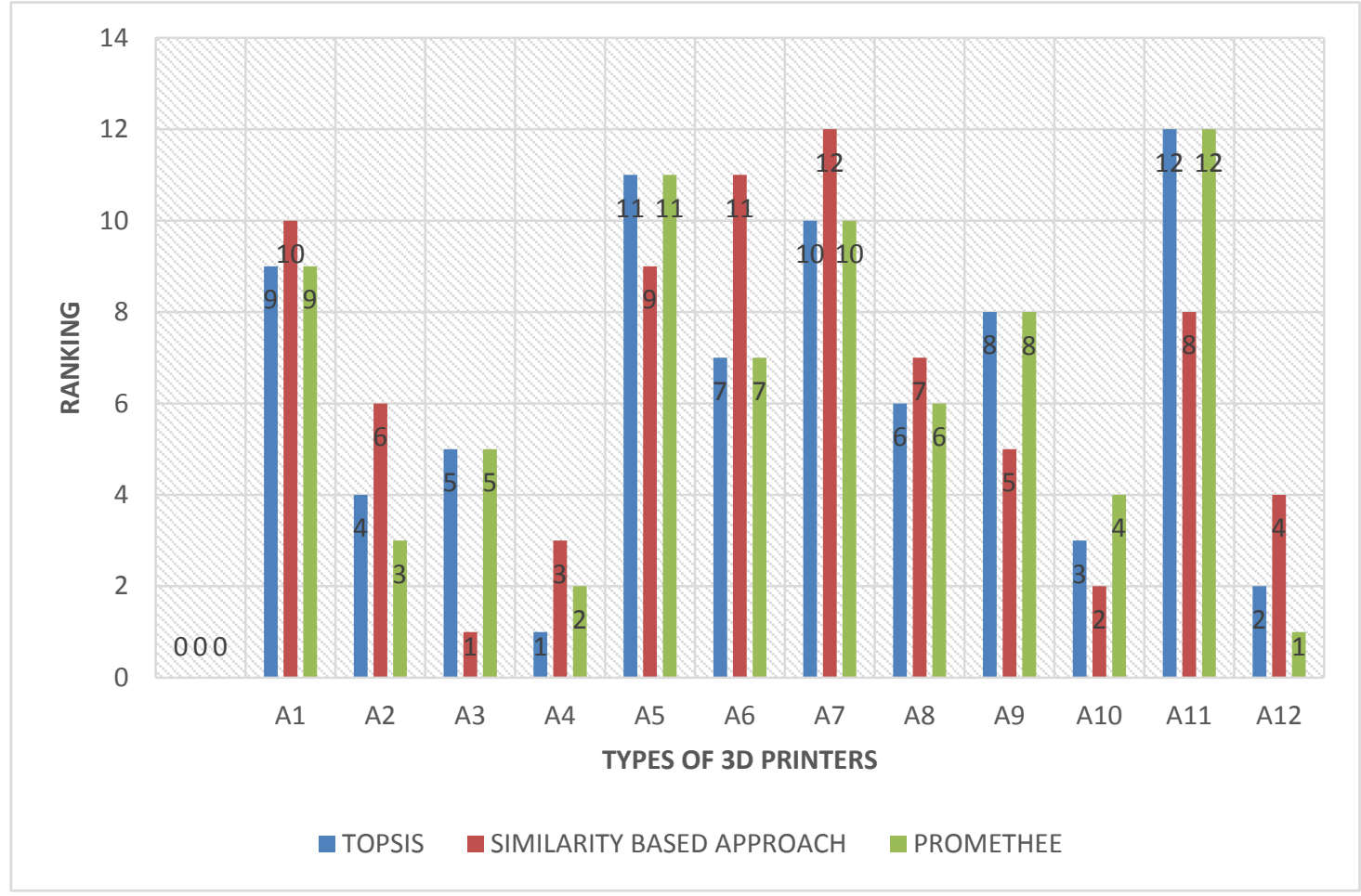

Fig. 5. Graphical analysis of Rankings

\section{Conclusion}

Three different MCDM techniques, namely TOPSIS, Similarity Approach and PROMETHEE, have been compared with respect to a chosen problem i.e. selection of 3D Printers, the relative weights of the associated criteria having been determined using ANP. Slight deviations are witnessed in the results given by the above three methods namely, TOPSIS, Similarity Based Approach and PPROMETHEE. XYZPRINTING DAVINCI 1.0 emerges out to be the best solution as per the TOPSIS method. ULTIMAKER 2 is the best solution as per the Similarity Based Approach. MBOT GRID emerges out to be the best solution as per the PROMETHEE Method. For both TOPSIS and PROMETHEE, the worst solution is the CUBIFY CUBEPRO, but for Similarity Method, the UP PLUS 2.0 is the worst solution. Further investigation, reveals that TOPSIS and PROMETHEE rankings are highly similar to a certain extent as seen in Table 10 and fig. 5, but results of the similarity based approach are markedly different. From the above problem and the varied solutions obtained from using different MCDM 
techniques, it can be inferred that under certain circumstances, the use of different MCDM methods sometimes highlight different alternatives as the most appropriate one, and will provide different ranking order of the alternatives. This may be because of the different aggregation and normalization procedures which the methods follow. In conclusion, it can be inferred that the considered MCDM techniques have their own specifics and advantages, which is why the choice of MCDM method becomes a rather complex decision.

\section{References}

Athawale, V. M., \& Chakraborty, S. (2010, January). Facility location selection using PROMETHEE II method. In Proceedings of the 2010 International Conference on Industrial Engineering and Operations Management (pp. 9-10).

Amponsah, S. K., Darkwah, K. F., \& Inusah, A. (2012). Logistic preference function for preference ranking organization method for enrichment evaluation (PROMETHEE) decision analysis. African Journal of Mathematics and Computer Science Research, 5(6), 112-119.

Brans, J. P., \& Vincke, P. (1985). Note-A preference ranking organization method: (The PROMETHEE method for multiple criteria decision-making). Management science, 31(6), 647-656.

Brans, J. P., \& Mareschal, B. (2005). PROMETHEE methods In Multiple criteria decision analysis: state of the art surveys (pp. 163-186). Springer New York

Bhutia, P. W., \& Phipon, R. (2012). Appication of ahp and topsis method for supplier selection problem. IOSR Journal of Engineering (IOSRJEN) Volume, 2, 43-50.

Campbell, T., Williams, C., Ivanova, O., \& Garrett, B. (2011). Could 3D printing change the world, Technologies, Potential, and Implications of Additive Manufacturing, Atlantic Council, Washington, DC.

Caterino, N., Iervolino, I., Manfredi, G., \& Cosenza, E. (2009). Comparative analysis of multi-criteria decision-making methods for seismic structural retrofitting. Computer-Aided Civil and Infrastructure Engineering, 24(6), 432-445.

Cheng, E. W., \& Li, H. (2004). Contractor selection using the analytic network process, Construction management and Economics, 22(10), 1021-1032.

Deng, H. (2007). A similarity-based approach to ranking multi-criteria alternatives, Third International Conference on Intelligent Computing, ICIC 2007, Qingdao, China, August 21-24, 2007. Proceedings, pp. 253-262.

Houshyar, A., \& White, B. (1997). Comparison of solution procedures to the facility location problem. Computers \& industrial engineering, 32(1), 77-87.

Hwang, C. L., \& Yoon, K. (1981). Methods for multiple attribute decision making. In Multiple Attribute Decision Making (pp. 58-191), Springer Berlin Heidelberg.

Karande, P., \& Chakraborty, S. (2012). Application of PROMETHEE-GAIA method for nontraditional machining processes selection. Management Science Letters, 2(6), 2049-2060.

Panda, B. N., Biswal, B. B., \& Deepak, B. B. L. V. (2014) Integrated AHP and fuzzy TOPSIS Approach for the Selection of a Rapid Prototyping Process under Multi-Criteria Perspective. 5th International \& 26th All India Manufacturing Technology, Design and Research Conference (AIMTDR 2014), IIT Guwahati, Assam, India.

Saaty, T. L. (1988). What is the analytic hierarchy process? (pp. 109-121), Springer Berlin Heidelberg

Saaty, T. L. (2001). Analytic network process, In Encyclopedia of Operations Research and Management Science (pp. 28-35), Springer US.

Saaty, T. L. (2004). Decision making - the analytic hierarchy and network processes (AHP/ANP). Journal of systems science and systems engineering, 13(1), 1-35.

Shahroudi, K., \& Rouydel, H. (2012). Using a multi-criteria decision making approach (ANP-TOPSIS) to evaluate suppliers in Iran's auto industry. International Journal of Applied Operational Research, 2(2), 37-48.

Shyur, H. J. (2006). COTS evaluation using modified TOPSIS and ANP. Applied Mathematics and Computation, 177(1), 251-259. 